\title{
Semantic Characteristics of the Concept "Tosca" in Modern Russian Linguistic Culture
}

\author{
Yulia Pogrebnyak ${ }^{1, *}$

\begin{abstract}
${ }^{1}$ Military Institute (Engineering and Technical) of Military Academy of Material and Technical Support named after General A.V. Khrulev, Sankt-Petersburg, Russia
\end{abstract} \\ *Corresponding author. Email: pyuma@yandex.ru
}

\begin{abstract}
In this article semantic components of the concept "tosca" are described as they are introduced in Internet statuses in contemporary Russian culture. The analysis of Internet statuses about tosca shows that the concept under consideration, being basic in contemporary Russian linguistic culture, has developed some new meanings in modern Russian linguistic culture.
\end{abstract}

Keywords: concept, internet status, notional component, figurative component, evaluative component,

tosca

\section{INTRODUCTION}

Internet status is a relatively new phenomenon in the conditions of modern life and, in our opinion, it can be defined as a new form of literary genre.

Online statuses occur when an Internet user projects an instant emotional or mental state onto a social network platform or group. A person who establishes a certain status in the network, accordingly, waits for a reaction to his/her emotional state. In addition, if his/her emotional state is negative, he/she will expect some form of psychological help from other Internet users.

Since online statuses characterize the psychological state of an individual, in our opinion, it is appropriate to refer to the definition of the word "status" in psychology. The encyclopedic dictionary "Psychological lexicon" gives the following definition of the word "status": lat. status — in social psychology - the position of the subject in the system of interpersonal relations, which determines his/her rights, duties and privileges. In different groups, the same individual may have different status. Significant differences in the status that an individual acquires in groups that differ in the level of development of the group, the content of activity and communication, often become causes of frustration, conflict, etc. The status is experimentally revealed by applying various sociopsychological methods. Important characteristics of the status are prestige and authority as a kind of recognition measure [1]

From the above definition, it is clear that the status of a person in society is a more or less stable and longterm position of the subject in various social groups.
Status determines the rights, duties, privileges of an individual, the level of his/her prestige and authority in certain social groups. The online status of an individual, in contrast to his/her real social and psychological status, is largely modeled on the basis of an idea that is far from reality. Moreover, this idea can be changed relatively quickly depending on the person's mood. A person can express his/her mood verbally using phrases that are easily available on the Internet. Online statuses are statements that are similar in form to such genres as the aphorism, maxim, apothegm and gnome. Internet statuses, being a popular phenomenon in modern life, have a number of characteristics that to a certain extent distinguish them from the above types of genres:

- beauty, brightness of the shape;

- rhythmic and syntactic completeness;

- originality of judgments;

- the presence of worldly wisdom based on experience;

- conciseness.

Very often, statuses on the Internet contain humor and elements of paradox. In our opinion, the difference between an online status and an aphorism is the absence of an author. Online statuses are less instructive, more down-to-earth compared to aphorisms. Some popular aphorisms, quotes, or sayings can also become statuses on the Internet.

Internet statuses thematically cover various areas of modern life: education, work, family, relationships between people (friendship, love), attitude to life in general. 


\section{II. "TOSCA" AS ONE OF THE BASIC CONCEPTS OF RUSSIAN CULTURE}

A. Vezhbitskaya emphasizes that in Russian culture the key words "fate", "soul" and "tosca" play an important role, they are the basic concepts of Russian culture. Along with the words "fate" and "soul", the nominee "tosca" is also a key word of Russian culture: it is commonly used, has many synonyms, and is often represented in literature, set expressions and folklore. A. Vezhbitskaya describes the concept "tosca" as a certain desire of a person for something better and his/her understanding of the impossibility of achieving this [2].

One of the famous authors who turned to the concept of "tosca" was N. Berdyaev. Despite the fact that the semantics of this word is very vague, the philosopher very accurately separates it from such nominees as "boredom", "fear", "horror", "sadness", etc. Longing is directed to the higher world, it is associated with loneliness and means non-alignment with the transcendental. There is hope in longing. Tosca is soft and lingering... [3].

N. A. Krasavsky also believes that the concept of "tosca" is culturally extremely significant for the Russian language consciousness. "It is necessary to point out such pronounced national specific categories of emotions in the Russian language as "грусть-тоска", "печаль-тоска". ... The specified Russian symbols of emotions belong to the class of non-equivalent vocabulary. This linguistic fact, in our opinion, is culturally symptomatic. It is a testimony to the deep detailed and specific elaboration of this group of emotions by the Russian consciousness" [4: 22].

N. A. Krasavsky connects the notional component of the concept "tosca" with the meanings of such words as" sadness"," longing"," anxiety"," despondency"," soul "and concludes that at the conceptual level, the meaning of the word "tosca" is blurred. N. A. Krasavsky, through an interpretive analysis of the specified nominee, identifies such semantic groups in the cognitive field of this emotion as: longing is death; the severity of longing, physical absorption, hopelessness, the absence of a producer of longing, etc. [4].

The origin of the word "tosca", as you can see from the online etymological dictionary, edited by $\mathrm{M}$. Vasmer, N. M. Shan, G. A. Krylov ascend to such meanings as "oppression; grief, sorrow; anxiety, worry," may be "vain, skinny, in vain", "squeeze" [5].

E. V. Dimitrova notes that the contents of the concept "tosca" has the following meanings: 'longing', 'sadness', 'boredom', 'depression', 'melancholy', 'anxiety', 'homesickness', 'sorrow for the loss', 'the pursuit of anything', 'longing for loved ones'.
The concept "tosca" has a lot of cultural connotations. It is associated with such images as 'eyes', 'face', 'voice, sound, speech', 'sigh', 'tears', 'heart', 'soul', etc. [6].

E. N. Davtyan and S. E. Davtyan, conducting research at the Department of clinical psychology and Department of psychiatry and drug treatment, cite the statement of the patient's endogenous depression (symptom of atrial boredom (tosca)):

"Compression of the heart, feeling as if the bellows of the accordion are being squeezed, and it is impossible to separate them...like there is a wound in the heart and pus from it comes out in little portions but the wound erupts... a feeling that the heart is bleeding... heaviness, aching pain accompanied by anxiety, sadness, guilt... The heart seemed to flatten, it became like a pancake...A feeling of emptiness in the breast, longing, sadness...".

Archaic images of Russian emotional words lead to the appearance of metaphors in the speech of patients and contain an indication that something torments them, burns, causing pain and suffering.

These images are associated in the minds of patients with a threat to their life or health [7].

We agree with V. I. Karasik's opinion that a concept has nominative, figurative and evaluative components [8]. Let us consider these components in the structure of the concept "tosca".

\section{NOTIONAL COMPONENT OF THE CONCEPT "TOSKA" IN MODERN RUSSIAN LINGUISTIC CULTURE}

The notional component of the concept "toska" in modern Russian linguistic culture is represented by the following semantic components.

- Tosca can be for something indefinite.

Longing is when you crave something, you don't know what... It exists, it is unknown and desirable, but it cannot be expressed in words (A. Exupery) [9].

All I feel now is some strange feeling of longing, for some unknown thing [10].

- A person usually longs for love when he/she is separated from his/her loved ones.

Oh, jealousy! What kind of torment are you preparing for me! There are no worse evils than the death of happiness and the anguish of separation... [11].

Melancholy is a terrible thing when thoughts run away into the distance... When someone loves someone, but he/she loves from afar... [10].

- Tosca accompanies loneliness. 
Such a pleasant melancholy. Something like the silence of a pine tree from which the birds have flown away.

What are the limits of your longing and your loneliness, if you dialed my number? [10]

- Jealousy breeds tosca.

Can you imagine how much trouble jealousy has brought to people? How much happiness it has destroyed, how much tosca it has created... [10].

What a terrible word - jealousy! How much suffering it brings! There is nothing worse than the tosca of separation and the death of happiness. [12].

- Tosca takes possession of a person regardless of his/her desire, and then can "leave" the person.

When I go through my memories, I'm afraid to stumble upon those that make me feel tosca (Sagan) [9].

My house is full of tosca. Apparently, its time has come (S. King) [9].

Tosca attacks with incredible force, the onslaught of which is difficult for me to restrain, and my heart burns with tears of sadness mixed with the time spent without him [11].

Tosca overcame. I started smoking again, drinking and looking for a man... [12].

Let me go, tosca, I am not your slave [9].

- Tosca is contagious

The most difficult thing when the soul is filled with tosca is not to infect any of your loved ones with it. [11].

- Tosca can be different.

The most tolerable of all kinds of tosca is to sleep under your blanket... [11].

Different people have different tosca. Some just sit and are ready to howl at the moon, and others are looking for a way out [10].

- Tosca is a feeling that is localized in the heart.

At the bottom of my heart, keeping resentment and tosca , I clench my fists and repeat: "I can do it "...[12].

Oh, why is my heart so sad?

Ah, why does tosca squeezes the chest?

The soul stubbornly craves positive emotions,

Instead of "alas", it wants "hurrah!" [10].

- Longing is visible in the eyes.

Tosca has darkened my eyes, and sadness fills my heart. [9]
You go where he can be, and you're having fun, but you're fooling yourself! You can look as good as you want, but no make-up will remove the longing from your eyes! [9].

\section{THE FIGURATIVE COMPONENT OF THE CONCEPT "TOSKA" IN MODERN RUSSIAN LINGUISTIC CULTURE}

The figurative component of the concept "toska" in modern Russian linguistic culture is represented by the following semantic components.

- Tosca is associated with tears, sadness, and pain.

Always alone, always sad, always longing, always in tears [12].

Look into my eyes and tell me what you see in them. Sadness, tosca, deception. Do you think it hurts? No, I'm used to it... [10].

One day it will all be over. The pain will pass. You will be able to calm the tosca and sadness. Don't give up! Everything will work out ... one day. [11].

Sadness and tosca always go together. And somewhere in the distance, hopelessness follows them [10].

- In autumn, tosca is felt especially acutely. Also, tosca usually comes at night, in rainy weather.

It is in the fall that the feeling of tosca comes. It comes with beautiful streets strewn with yellow leaves, and couples holding hands tightly. [12]

The city is asleep, the lights are on. Together we are - but we are alone! The noise of the rain is depressing. I feel tosca without you! [12].

I feel tosca at any time of the day, but especially at night it's hard without you. I miss you, I miss you, and I wait, but you won't come, I won't bring you back... [10].

\section{THE EVAlUative COMPONENT OF THE CONCEPT "TOSCA" IN MODERN RUSSIAN LINGUISTIC CULTURE}

The evaluative component of the concept "tosca" in modern Russian linguistic culture is represented by the following semantic components.

- Tosca is a destructive feeling, it consumes people.

Tosca slowly but surely eats me from the inside...there is so much pain in my heart that it seems that soon I will not stand it ... and I try to smile, hide my tears under insincere laughter. I'm just afraid that I won't be understood [11]. 
Tosca consumes me... There's a pain in my heart that can't be eased. I don't try to smile anymore - I try not to cry. And it gets even worse from the realization of the fact that no one will understand me... [10].

- Tosca - a negative feeling, people need to work on themselves, so as not to feel tosca.

Happy even in his anguish is he to whom the Lord has given a soul worthy of love and misery. Victor Hugo [9].

And although... To hell with the boredom! To hell with the pathos! May all my enemies die! Life is beautiful! [9].

Work silences boredom better than drinking (T. Edison) [12].

If you are lazy - you will fall into tosca. Then you'll lose your taste for life. And that's it, the end (D. Dashner) [9].

- People should end love relationships with friendship to protect themselves from longing.

Relationships should end with friendship, it is not so terrible, because if a person is not indifferent to you, then you can give him freedom, and protect yourself from eternal tosca, as it is also very painful to feel tosca [11].

Ending a relationship with friendship isn't as bad as it sounds. If you really care about him, then it will not be difficult to make him free and shove your tosca deeper [10].

- The Internet creates tosca.

The Internet makes me feel tosca. I do not know how this happens... If you stay at home at the computer tosca rolls over. And when you manage to go somewhere to take a walk - everything seems to be fine [10].

The Internet... All I do is turn it on and off... Just turn it off - immediately there are desires to do something, go for a walk, read a book...I turn it on and after a few minutes I again have a feeling of tosca [11].

Sometimes, a wild tosca will cover you... I get up, go to the window, look at the stars and decide to change my life forever! Well, and then back to the computer [12].

- Tosca is relieved by alcohol.

You can be feel tosca, then you can look out the window sadly, or you can drink wine! What will you choose? [9].

- People hide their tosca behind a smile.
Even in such dreary moments, I smile... I am a jester, I am a harlequin [12].

\section{CONCLUSION}

The analysis of Internet statuses about tosca showed that this concept is basic for the modern Russian person.

The concept "tosca" has strong conceptual, figurative and evaluative components that are closely intertwined. The conceptual component of the concept "tosca" in modern Russian Internet statuses includes the idea of tosca as a feeling that is localized in the heart and reflected in the eyes, and which takes possession of a person regardless of his/her desire. Tosca can be for something indefinite, often for love. Tosca accompanies loneliness, separation, jealousy.

The figurative component of the concept "toska" in modern Russian linguistic culture is expressed in the connection of tosca with autumn, rain, dampness. Tosca is associated with tears, sadness and pain.

The evaluative component of the concept "tosca" in modern Russian linguistic culture is mainly represented by the assessment this feeling as negative and destructive, which should be avoided if possible. To do this, people need to work more. It is better to end love relationships with friendship to protect oneself from tosca. People should spend less time on the Internet to avoid tosca. Alcohol can temporarily relieve tosca, but this is not the best remedy.

The analysis of Internet statuses shows that in comparison with the traditionally distinguished components of the concept "tosca" in modern Russian linguistic culture, new meanings have appeared: longing is generated mainly by the lack of love, separation, jealousy and loneliness, which are aggravated by the Internet, depriving people of fullfledged live communication.

\section{References}

[1] Psychological lexicon. An encyclopedic dictionary in six volumes. Edited by M. Yu. Kondratiev/Ed. - compiled by L. A. Karpenko. Under the general editorship of A.V. Petrovsky. - M. Per. s engl., 2006. - 176 p.

[2] A. Vezhbitskaya Understanding of cultures through the medium of key words / Translated from English by A. D. Shmeleva. - M. Languages of Slavic Culture, 2001-288 p.

[3] N. Berdyaev. Self-knowledge. Moscow: EKSMO-Press; Kharkiv: Folio, 1998. - 620 p.

[4] N. A. Krasavsky Concept "toska" in Russian linguoculture. Proceedings of the Volgograd State Pedagogical University: Volgograd Volgograd State Social and Pedagogical University, 7 (41) Year: 2009. P. 20-23.

[5] The origin of the word tosca. - URL (https://lexicography.online/etymology/т/тоска). 
[6] Dimitrova E. V. Toska. // Anthology of concepts. Edited by V. I. Karasik, I. A. Sternin. Volume 1. Volgograd: Paradigm, 2005. P. 268-273.

[7] Davtyan E. N., Davtyan S. E. Emotional concepts of the Russian language: picture of the world in norm and in pathology. Psychiatry and psycho pharmacotherapy. 2016; 18 (2): P. 48-53.

[8] Karasik V. I. Language circle: personality, concepts, discourse. - Volgograd: peremena, 2002. - $480 \mathrm{p}$.

[9] Statuses and quotes. - URL : (https://statusycitaty.ru/

[10] New statuses about longing. - URL : (https://novyestatusy.ru/statusy-pro-tosku.html)

[11] Zitate. Quotes and statuses with meaning. Statuses about longing. - URL : (https://icitata.ru/statusy-pro-tosku/)

[12] Million statuses. $\quad-\quad$ URL

(https://millionstatusov.ru/statusy/toska.html) 